\title{
Effect of Papain and Bromelain Enzymes on Shear Bond Strength of Composite to Superficial Dentin in Different Adhesive Systems
}

\author{
Farahnaz Sharafeddin ${ }^{1}$, Mina Safari ${ }^{2}$
}

\begin{abstract}
Aim: The aim of this study was to compare different dentin treatments and adhesive systems on shear bond strength (SBS) of composite to superficial dentin.

Materials and methods: In this in vitro experimental study, 60 extracted human upper premolars were cut $0.5 \mathrm{~mm}$ deep under occlusal DEJ and were randomly divided into six groups $(n=10)$ based on the method of dentin treatment and adhesive system: (A) two steps self-etch adhesive system (Clearfil SE bond) and (B) two steps of total etch bonding system (Adper single bond 2). (C) 10\% papain + Clearfil SE bond. (D) $10 \%$ papain + Adper single bond 2. (E) $6 \%$ bromelain + Clearfil SE bond. (F) $6 \%$ bromelain + Adper single bond 2. Then, a plastic mold was placed on dentin and filled with resin composite. Shear bond strength (MPa) was tested by a universal testing machine (Zwick/Roell Z020, Germany), and the data were statistically analyzed by two-way ANOVA and Tukey's test $(p<0.05)$ and were applied for mean comparison.

Results: A significant difference was detected in the SBS evaluation between the applied adhesive systems $(p=0.0007)$. The SBS was also significantly affected by the interaction of treatment and etching techniques $(p=0.028)$. The group with $10 \%$ papain as a deproteinizing agent before the self-etching adhesive system showed the highest SBS $(p=0.029)$. There were no significant differences considering the specimens exposed to papain before the total etch adhesive system $(p=0.13)$, and the specimens were exposed to bromelain enzyme before self-etch and total etch adhesive systems ( $p=0.25, p=0.84$, respectively).

Conclusion: Papain enzyme treatment with the self-etch adhesive system increased the SBS value. Additionally, the application of bromelain enzyme as dentin treatment before two adhesive systems and papain before total etch adhesive system had no effect on the SBS of composite to superficial dentin.

Clinical significance: Application of adhesive systems and dentin treatment can influence the bond strength.

Keywords: Adhesive system, Bromelain, Papain, Shear strength.

The Journal of Contemporary Dental Practice (2019): 10.5005/jp-journals-10024-2646
\end{abstract}

\section{INTRODUCTION}

The longevity of restorations and their bond strength depends on the extent of polymerized resin infiltrating into the demineralized dentin. ${ }^{1,2}$ The dentin bonding agents such as total etch and selfetch, which are employed may not completely penetrate into the demineralized dentin. ${ }^{1}$ The application of phosphoric acid etching gels in total etch adhesive systems removes the smear layer completely. It could increase the resin infiltration into the demineralized collagen network, but it poses two major challenges: the excessive dehydration of the dentin collagen and the depth of demineralization beyond the resin-infiltration level resulting in poor hybridization. ${ }^{1}$ To overcome these problems, a number of self-etch adhesive systems were introduced based on a smear layer-modifying bonding strategy. Both demineralization and resin infiltration processes occur simultaneously. The depth of demineralization with self-etch adhesive systems is less comparable to total etch adhesive systems. ${ }^{3}$

The discrepancy between depth of dentin demineralization after the acid-etching and depth of resin infiltration can provide a pathway for hydrolytic degradation. ${ }^{2,3}$ One of the responsible factors for the occurrence of this degradation is imperfect infiltration of resin monomers into unsupported collagen networks. This network generates an area containing collagen in the hybrid layer without any support of either minerals or resins. ${ }^{4}$ The feasible solution to eliminate or minimize this problem would

\begin{abstract}
1,2Department of Operative Dentistry, School of Dentistry, Shiraz University of Medical Sciences, Shiraz, Iran

Corresponding Author: Mina Safari, Department of Operative Dentistry, School of Dentistry, Shiraz University of Medical Sciences, Shiraz, Iran, Phone: +98 9177891590, e-mail: mi_safari@sums.ac.ir

How to cite this article: Sharafeddin F, Safari M. Effect of Papain and Bromelain Enzymes on Shear Bond Strength of Composite to Superficial Dentin in Different Adhesive Systems. J Contemp Dent Pract 2019;20(9):1077-1081.
\end{abstract}

Source of support: Shiraz University of Medical Sciences

Conflict of interest: None

be the use of a proteolytic agent, known as deproteinization, which removes organic components in dentin and changes its chemical composition. Therefore, the surface energy of the dentin is improved owing to higher hydroxyapatite content and diffusion enhancement of adhesive monomers through dentin. $^{1-3}$

Among the substances with similar activities, papain is a dominant one introduced into dentistry as chemical removing caries without any harmful effects on tissues. Papain is extracted from the ripe fruit of the Carica papaya, belonging to the Caricaceae family. It is a proteolytic cysteine enzyme having antibacterial and anti-inflammatory properties. ${ }^{5,6}$ It has been reported that the use of 
$10 \%$ papain as a deproteinizing agent before acid etching increases the bond strength by removing organic elements. ${ }^{7}$ Another study indicated that the highest bond strength values were attained with $8 \%$ and $10 \%$ papain. $^{5}$

Bromelain is another deproteinizing enzyme (proteases), which was commercially obtained from the fruit or stem of pineapple. ${ }^{8}$ Bromelain enzyme can improve the bond strength when applied after acid etching in dentin. ${ }^{4}$ However, there is limited information on its effectiveness in improving the bond strength before etching. Therefore, the present study aimed to assess the deproteinizing effects of bromelain and papain enzyme on the shear bond strength before the application of total etch and self-etch adhesive systems.

\section{Materials and Methods}

Sixty extracted human maxillary premolar teeth without any defects, cracks, caries and restoration were collected in one month. The teeth were washed under running water to remove any debris and tissues, stored in $0.1 \%$ thymol solution at $4^{\circ} \mathrm{C}$ for a week. Afterward, the teeth were thoroughly washed with tap water and then embedded in self-cure acrylic resin up to the cement-enamel junction of the teeth (Acropars, Iran) in a way that occlusal surface was in parallel with acrylic resin surface and ready for surface preparation.

After resin was polymerized, the samples were cut under water coolant with diamond disc (D and Z, Germany) on the occlusal surface, $0.5 \mathrm{~mm}$ depth under central pit. In addition, a 600 grit silicon carbide paper was applied to obtain uniformity and polished superficial dentin. The teeth were randomly divided into six groups $(n=10)$ based on the method of dentin treatment and adhesive system.

The specimens were treated with one of the following procedures summarized in Table 1.

Group A: Two steps of the self-etch adhesive system (Clearfil SE bond, Kuraray, Japan) were used by applying a primer with microbrush for 20 seconds and dried with mild air flow, then the bond was applied and a uniform bond film was created with a gentle air flow.

Group B: Dentin surface was etched with $37 \%$ phosphoric acid (Denfil, Vericom, Korea) for 15 seconds, and rinsed for 10 seconds with distilled water. Excess water was blotted using a cotton pellet. Two steps of the total etch system (Adper single bond 2, 3M ESPE, USA) were applied as two consecutive coats of adhesive to etched dentin for 15 seconds with gentle agitation using a fully saturated microbrush for 5 seconds to evaporate solvents.

Group C: $10 \%$ papain (ORGANIKA, Canada) prepared by $10 \mathrm{~g}$ of papain powder in $100 \mathrm{~mL}$ distilled water was used for the dentin

Table 1: Dentin treatments in the study

\begin{tabular}{|c|c|}
\hline Treatment & Description \\
\hline Group A & Clearfil SE bond + composite resin \\
\hline Group B & $\begin{array}{l}37 \% \mathrm{H}_{3} \mathrm{PO}_{4}, 15 \text { seconds }+ \text { Adper single bond } 2+ \\
\text { composite resin }\end{array}$ \\
\hline Group C & $\begin{array}{l}10 \% \text { papain } 60 \text { seconds + Clearfil SE bond + } \\
\text { composite resin }\end{array}$ \\
\hline Group D & $\begin{array}{l}10 \% \text { papain } 60 \text { seconds }+37 \% \mathrm{H}_{3} \mathrm{PO}_{4}, 15 \text { seconds } \\
+ \text { Adper single bond } 2+\text { composite resin }\end{array}$ \\
\hline Group E & $\begin{array}{l}6 \% \text { bromelain } 60 \text { seconds + Clearfil SE bond + } \\
\text { composite resin }\end{array}$ \\
\hline Group F & $\begin{array}{l}6 \% \text { bromelain } 60 \text { seconds }+37 \% \mathrm{H}_{3} \mathrm{PO}_{4 \prime} \\
15 \text { seconds }+ \text { Adper single bond } 2+\text { composite resin }\end{array}$ \\
\hline
\end{tabular}

treatment with a microbrush for 60 seconds. The papain was washed for 15 seconds with distilled water and then air dried. Afterward, Clearfil SE bond was applied as it was employed in the group A.

Group D:Dentin surface treatment with $10 \%$ papain was applied for 60 seconds with a microbrush. The papain was washed for 15 seconds with distilled water, air dried, and followed by the same procedure in the group $B$.

Group E: $6 \%$ bromelain prepared by $6 \mathrm{~g}$ of bromelain powder in $100 \mathrm{~mL}$ distilled water was used for the dentin treatment with a microbrush for 60 seconds. Then, it was washed for 15 seconds with distilled water and air dried. Afterward, Clearfil SE bond was applied as it was employed in the group A.

Group F: Dentin surface treatment with $6 \%$ bromelain was used for 60 seconds with a microbrush. Bromelain was washed for 15 seconds with distilled water, air dried, and followed by the same procedure in the group $B$.

Adhesive system was cured for 10 seconds from occlusal surface using an emitting diode (LED) polymerizing unit (Monitex, Bluelex, GT 1200, Taiwan) at the wavelength of $470 \mathrm{~nm}$ and light intensity of $1200 \mathrm{~mW} / \mathrm{cm}^{2}$. After completion of the adhesive procedures, a plastic mold with $2 \mathrm{~mm}$ high and $3 \mathrm{~mm}$ internal diameter was placed over the prepared dentin surface. Then resin composite (Filtek Z-350, $3 M E S P E, U S A)$ was inserted into the plastic mold in one incremental horizontal layer and was cured for 20 seconds from the occlusal surface. Then, the plastic mold was removed by scalpel.

Figure 1 shows all the specimens. To simulate the oral environment, the specimens were stored at $37^{\circ} \mathrm{C}$ in distilled water for 24 hours in an incubator (ES 250 Nuve, Turkey) before testing. Afterward, as Figure 2 shows, the specimens were individually transferred to the universal testing machine (Zwick/Roell Z020, Germany) and subjected to SBS (MPa) analysis at a crosshead speed of $1.0 \mathrm{~mm} /$ minute.

The two-way ANOVA, including six different treatments were performed for data analysis, and Tukey's test was applied for pairwise comparison $(p<0.05)$. The statistical analysis was conducted using the SPSS software, version 21 for Windows (SPSS Inc., Chicago, IL, USA).

\section{Results}

Two-way ANOVA test showed significant differences between the adhesive systems in SBS (MPa), and the self-etch adhesive system had significantly higher SBS than the total etch adhesive system

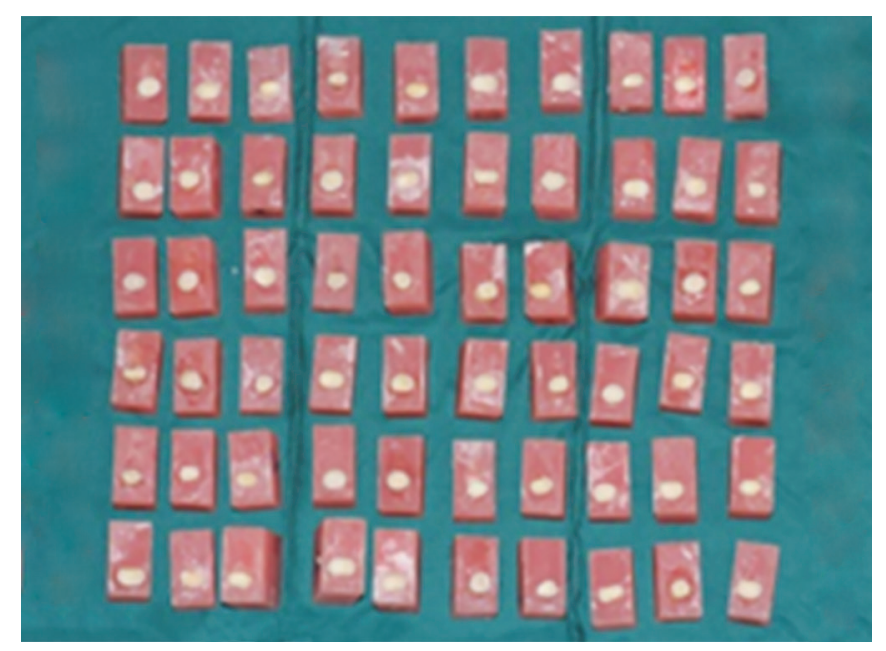

Fig. 1: All specimens 


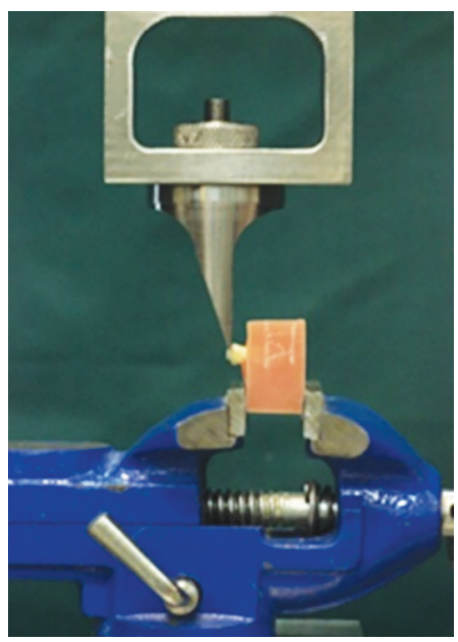

Fig. 2: Universal testing machine

Table 2: Mean and Std. deviations of shear bond strength (MPa) in all groups

\begin{tabular}{llc}
\hline Treatment & Adhesive system & Mean \pm Std. deviation \\
\hline No treatment & Self etch & $12.382 \pm 2.43^{\mathrm{ab}}$ \\
& Etch and rinse & $9.480 \pm 1.93^{\mathrm{bc}}$ \\
Papain & Self etch & $14.850 \pm 2.22^{\mathrm{a}}$ \\
& Etch and rinse & $7.789 \pm 1.34^{\mathrm{c}}$ \\
Bromelain & Self etch & $13.645 \pm 3.84^{\mathrm{a}}$ \\
& Etch and rinse & $9.692 \pm 2.32^{\mathrm{bc}}$ \\
\hline
\end{tabular}

Different letters show significant differences (Tukey test) in groups

( $p=0.0007$ ). Table 2 shows the mean and standard deviation of SBS in all groups. The highest SBS was noted in the group $C$, which papain enzyme was applied before the self-etch adhesive system $(p=0.029)$. There were no significant differences in the groups considering the specimens exposed to papain before total etch adhesive system ( $p=0.13$ ). However, statistically significant differences were not noted in bromelain treated groups with the self-etch adhesive system $(p=0.25)$ and with the total etch adhesive system ( $p=0.84$ ) (Fig. 3).

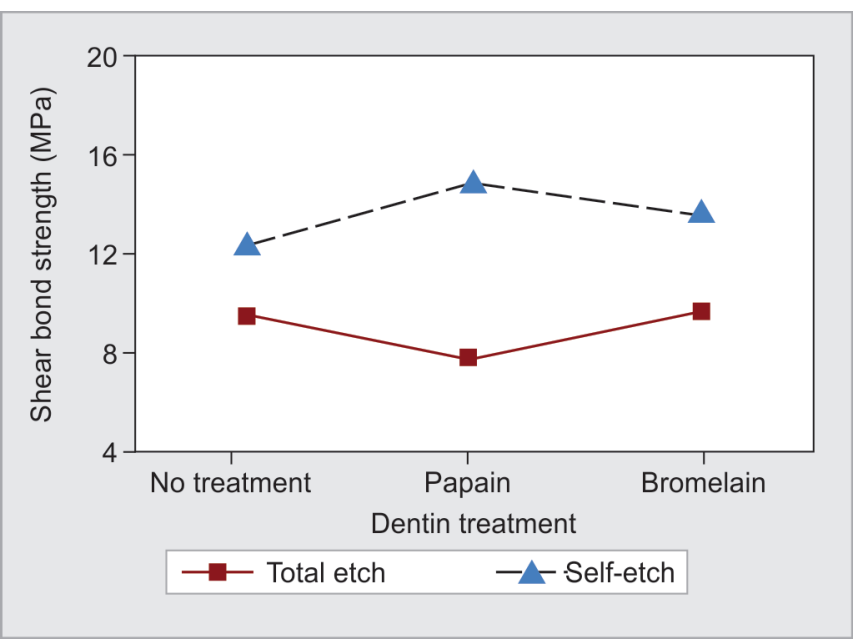

Fig. 3: Line diagram representation of shear bond strength (MPa) of all groups

\section{Discussion}

Some factors such as incomplete infiltration of adhesive material in the demineralized dentin, permeability of adhesive systems, and degradation of collagen fibers unimpregnated with adhesive systems have influence on the stability of hybrid layer. ${ }^{1,9,10}$ Dissolution and removal of this collagen fibers were used first with sodium hypochlorite after acid conditioning to increase the stability of restorative interface; the technique is known as deproteinization. ${ }^{11-13}$ This study assessed and compared the SBS of papain and bromelain enzyme, as two new deproteinizing agents, in total etch and selfetch adhesive systems at superficial dentin. The desirability for the shear test is due to its easy performance, and requirement of minimal equipment and specimen preparation ${ }^{14}$ therefore, we conducted this experiment with the shear bond test.

Our findings showed significant differences in the SBS evaluation between the applied adhesive systems. Total etch bonding system had a separate etching step eliminating the smear layer and mineral contents of dentin to $5-8 \mu$ depth. It increases the permeability of dentin and penetration of adhesive monomers. In addition, etching with phosphoric acid in total etch system results in formation of longer and thicker resin tags compared to those in self-etch system. ${ }^{15}$ Incomplete removal of the smear layer in selfetch adhesives exhibits a significant reduction in postoperative sensitivity. ${ }^{3}$ According to $\mathrm{pH}$ ranking, the Clearfil is regarded as one mild aggressiveness compared to other self-etching systems. This primer presents higher $\mathrm{pH}$ than the phosphoric acid gel. ${ }^{16}$ Some studies have reported that quality of the hybrid layer generated by self-etch systems is much better than that produced by total etch systems ${ }_{1}^{17-19}$ being consistent with our present study results in which that self-etch system revealed better actions on superficial dentin in SBS. This outcome is probably due to phosphoric acid as etchant in total etch systems is a strong acid that can be more invasive for dentin, which is referred to dentin desiccation and demineralization beyond resin infiltration. It seems that the technique-sensitive procedure and failure in removing all residual water entrapped in demineralized dentin cause poor polymerized resin in total etch systems. In the present study, the SBS was significantly affected by the interaction between dentin treatment and adhesive systems.

Agrawal et al. ${ }^{20}$ revealed that $10 \%$ papain was effective in deproteinizing surface before acid etching and enhancing the shear bond strength, but they observed no role of $10 \%$ papain in deproteinizing agent after acid etching on the SBS. According to the results, we applied two deproteinizing agents before acid etching conditioning.

Based on our results, the groups with $10 \%$ papain as dentin treatment before the self-etch adhesive system showed the highest SBS, which is in agreement with the previous study findings. ${ }^{9}$ The improvement of the bond strength values could be ascribed to dissolution of collagen fibrils and change of its composition that may result in better monomer diffusion by increasing dentin permeability.

The present study results differ from the findings by Piva et al. ${ }^{16}$ who observed that papain had adversely affected the bond of Clearfil SE bond to dentin. This difference may be due to lack of a rinsing step in their study; therefore, the remnants of papain could stagnate on the dentin surface and interfere with the bonding mechanism of self-etching adhesive. Papain application before total etch systems resulted in diminishing SBS in comparison to other groups in the present study however, the differences were not statistically significant. These findings corroborate the studies 
conducted by Lopes et al., ${ }^{21}$ in which papain did not affect the bonding of the total etch adhesive system. Our finding is consistent in part with the results of some studies showing that papain has no effect on the bond of total etch and self-etch systems to demineralize dentin. ${ }^{16,22,23}$

This outcome might be owing to phosphoric acid, which is strong enough to remove collagen fiber totally. In addition, the application of deproteinization agent has not been effective in permeability of dentin and formation of good hybrid layers. However, in the self-etch adhesive system that we used in the current study, papain could help to remove collagen fiber since the primer of Clearfil SE bond has higher $\mathrm{pH}$ than phosphoric acid and cannot remove the smear layer completely.

Dayem et al. ${ }^{8}$ revealed that bromelain enzyme application on conditioned dentin decreased the values of the global leakage score significantly. In another study, removal of unsupported collagen fiber with bromelain enzyme after acid etching improved the SBS. ${ }^{4}$ Hasija et al. ${ }^{24}$ reported that deproteinization conducted with bromelain exhibited effective bond strength as compared to papain, but it was not statistically significant. However, in our study, there were no significant differences between the specimens exposed to bromelain enzyme before two adhesive systems, which could be attributed to the different step of applying deproteinization agent as we applied it before etching. Nevertheless, in the test conducted by Hasija et al. ${ }^{24}$ deproteinization agent was employed after acid etching. In addition, different adhesive systems used in these studies influence bond strength. Different concentration of the deproteinizing agent and the surface treatments may produce different results. Hasija et al. ${ }^{24}$ used "Carie Care" containing $86.9 \%$ papain gel as the deproteinizing agent and enamel of primary molar, which was different from that of our study.

This study was done in in vitro condition and could not simulate oral condition such as water sorption, masticatory cycle, and $\mathrm{pH}$ changes; therefore, generalization of the results must be done carefully. There is limited information concerning the effect of papain and bromelain on the topography of demineralized dentin, and effect of different concentrations of these enzymes on deep dentin compared to superficial dentin; hence, further tests and clinical trials are recommended for these enzymes before its clinical usage.

\section{Conclusion}

Considering the limitations of the present study, 10\% papain gel increased the shear bond strength of composite to superficial dentin in the self-etch adhesive system. Meanwhile, the application of bromelain enzyme as dentin treatment, before self-etch and total etch adhesive systems and papain before the total etch system had no influence on the shear bond strength composite to superficial dentin. In this study, the bond strength results were significantly influenced by the application of adhesive systems and the interaction of dentin treatments and bonding systems.

\section{Clinical Significance}

Application of adhesive systems and dentin treatments can influence the bond strength.

\section{ACKnowledgments}

The authors thank the Vice-Chancellery of Research Shiraz University of Medical Science for providing the financial support of this research (Project Code: 1396-01-76-14574). The authors would like to thank the Biomaterial Research Center and Mrs. Baghery for testing specimens and Dr Vosooghi for conducting the statistical analysis.

\section{References}

1. Farghal NS, Abdalla Al, et al. The effect of combined application of new dentin desensitizing agent and deproteinization on dentin permeability of different adhesive systems. Tanta Dent J 2013 Dec;10(3):138-144.

2. Dayem RN. Assessment of the penetration depth of dental adhesives through deproteinized acid-etched dentin using neodymium:yttriumaluminum-garnet laser and sodium hypochlorite. Lasers Med Sci 2010 Jan;25(1):17-24. DOI: 10.1007/s10103-008-0589-4.

3. Alshaikh $\mathrm{KH}, \mathrm{Hamama} \mathrm{HHH}$, et al. Effect of smear layer deproteinization on bonding of self-etch adhesives to dentin: a systematic review and meta-analysis. Restor Dent Endod 2018 May;43(2):1-16. DOI: 10.5395/ rde.2018.43.e14.

4. Chauhan K, Basavanna RS, et al. Effect of bromelain enzyme for dentin deproteinization on bond strength of adhesive system. J Conserv Dent 2015 Sep-Oct;18(5):360-363. DOI: 10.4103/0972-0707.164029.

5. Pithon MM, Ferraz CS, et al. Effect of different concentrations of papain gel on orthodontic bracket bonding. Prog Orthod 2013 Aug;14(22):1-5. DOI: 10.1186/2196-1042-14-22.

6. Khattab NMA, Omar OM. Papain-based gel for chemo-mechanical caries removal: influence on microleakage and microshear bond strength of esthetic restorative materials. Am J Sci 2012 Jan;8(3):391-399.

7. Pithon MM, de Souza Ferraz C, et al. Effect of $10 \%$ papain gel on enamel deproteinization before bonding procedure. Angle Orthod 2012 May;82(3):541-545. DOI: 10.2319/062911-423.1.

8. Dayem RN, Tameesh MA. New concept in hybridization: Bromelain enzyme for deproteinizing dentin before application of adhesive system. Smile Dent J 2013 Oct-Dec;8(1):18-23.

9. Uceda-Gómez N, Loguercio $A D$, et al. Long-term bond strength of adhesive systems applied to etched and deproteinized dentin. J Appl Oral Sci 2007 Nov-Dec;15(6):475-479. DOI: 10.1590/S167877572007000600004.

10. Ghonaim AF, Abdelmohsen MM, et al. The effect of deproteinization of dentin surface on the micro-shear bond strength to dentin. Med J Cairo Univ 2014 Jun;82(2):31-35.

11. Toledano $\mathrm{M}$, Perdigão J, et al. Influence of $\mathrm{NaOCl}$ deproteinization on shear bond strength in function of dentin depth. Am J Dent 2002 Aug;15(4):252-255.

12. Toledano $\mathrm{M}$, Perdigão J, et al. Effect of dentin deproteinization on microleakage of Class V composite restorations. Oper Dent 2000 Nov-Dec;25(6):497-504.

13. Erhardt MC, Osorio E, et al. Influence of dentin acid-etching and $\mathrm{NaOCl}$-treatment on bond strengths of self-etch adhesives. Am J Dent 2008 Feb;21(1):44-48.

14. Aguilera FS, Osorio R, et al. Bonding efficacy of an acetone/based etch-and-rinse adhesive after dentin deproteinization. Med Oral Patol Oral Cir Bucal 2012 Jul;17(4):649-654.

15. Pashley DH, Tay FR, et al. State of the art etch-and-rinse adhesives. Dent Mater 2011 Jan;27(1):1-16.

16. Piva E, Ogliari FA, et al. Papain-based gel for biochemical caries removal: influence on microtensile bond strength to dentin. Braz Oral Res 2008 Oct-Dec;22(4):364-370.

17. Giachetti L, Bambi C, et al. SEM qualitative evaluation of four self-etching adhesive systems. Minerva Stomatol 2005 Jul-Aug; 54(7-8):415-428.

18. Waidyasekera $K$, Nikaido $T$, et al. Reinforcement of dentin in self-etch adhesive technology: a new concept. J Dent 2009 Aug;37(8):604-609. DOI: 10.1016/j.jdent.2009.03.021.

19. Ozer F, Blatz MB. Self-etch and etch-and-rinse adhesive systems in clinical dentistry. Compend Contin Educ Dent 2013 Jan;34(1):12-14.

20. Agarwal RM, Yeluri R, et al. Enamel deproteinization using Papacarie and $10 \%$ Papain gel on shear bond strength of orthodontic brackets before and after acid etching. J Clin Pediatr Dent 2015 Summer;39(4):348-357. DOI: 10.17796/1053-4628-39.4.348. 
21. Lopes MC, Mascarini RC, et al. Effect of a papain-based gel for chemomechanical caries removal on dentin shear bond strength. J Dent Child 2007 May-Aug;74(2):93-97.

22. Gianini RJ, do Amaral FL, et al. Microtensile bond strength of etchand-rinse and self-etch adhesive systems to demineralized dentin after the use of a papain-based chemomechanical method. Am J Dent 2010 Feb;23(1):23-28.
23. Rosyida NF, Suparwitri S, et al. Improving Tensile Bond Strength of Orthodontic Bracket by Applying Papain Gel as an Email Deproteinization Agent. J Dent Indones 2017 Dec;24(3): 70-74.

24. Hasija P, Vinod S, et al. Deproteinizing Agents as an Effective Enamel Bond Enhancer-An in Vitro Study. J Clin Pediatri Dent 2017 Jun;41(4):280-283. 